\title{
Lima Barreto e Evaristo Carriego: visões literárias de dois subúrbios latino- americanos (1900-1920)
}

\author{
Gabriela Hardtke Böhm ${ }^{1}$
}

RESUMO: O artigo analisa a representação do subúrbio na literatura de dois escritores latino-americanos. Evaristo Carriego (1883 - 1912) e Afonso Henriques de Lima Barreto (1881- 1922) "fundaram" a representação de bairros nas literaturas argentina e brasileira, respectivamente, e deram ao espaço em que viviam e conviviam feições distintas por meio de sua arte. A partir de dois exemplos recolhidos nas obras destes autores, procura-se identificar os traços distintivos de cada um dos espaços urbanos.

ABSTRACT: The article analyzes the representation of the suburb in the literature two Latin American writers. Evaristo Carriego (1883 - 1912) and Afonso Henriques de Lima Barreto (1881 - 1922) "founded" the representation in urban literature Argentina and Brazil, respectively, and gave the space in which they lived and lived through distinguishing features of his art. From two examples from the works of these authors, we seek to identify the distinctive features of each of the urban spaces.

PALAVRAS-CHAVE: literatura latino-americana; subúrbio; poesia; crônica

KEYWORDS: Latin American literature; suburb; poetry; chronic

Se existisse uma lógica a ser seguida na investigação da arte literária, esta nos diria que seria improvável encontrar pontos de contato entre um prosador e um poeta. Muito menos entre dois literatos de países que, embora pertencentes ao continente sulamericano, sofreram distintos processos de colonização. No entanto, tal comparação torna-se um objeto de pesquisa pertinente na medida em que muito mais do que pontos de contato, almeja-se mapear o que diferencia as representações dos subúrbios ou arrabaldes justamente em duas nações que, no início do século XX, ocupavam posição periférica nos mapas econômico e cultural. Brasil e Argentina, à época comemorando seus respectivos centenários de independência política, ainda eram conhecidos mais como destino de grandes contingentes migratórios e menos pela sua pujança econômica

\footnotetext{
${ }^{1}$ Doutoranda em Teoria Literária - Universidade Federal de Santa Catarina
} 
ou pela produção artística que faziam chegar à Europa. Era o contrário disso que acontecia. Jorge Schwartz (1983) afirma que a vanguarda dos países periféricos, à época de Oswald de Andrade, Oscar Quiroga e Oliverio Girondo, dirigia seus olhares para Paris, evitando cruzá-los entre si. Para Rivas (2001), o prestígio da capital francesa mais do que Londres e Berlim — "era grande sobre as elites crioulas, cuja corrente modernizadora, tanto na Espanha como em Portugal, reclamava, ela própria, o modelo francês; daí a tentação dessas jovens nações de beberem diretamente na fonte francesa" (p. 100). Não é o caso dos dois autores que intentamos cotejar aqui. Eles nunca deixaram seus países, tampouco circularam fora dos limites de sua região. Dois elos ligam essas duas figuras da história literária do cone-sul: o tempo e o espaço territorial que representam em sua arte.

Afonso Henriques de Lima Barreto (1881-1922), prosador e cronista carioca, pode-se dizer, foi contemporâneo do poeta entrerriano Evaristo Carriego (1883-1912). Ambos nasceram no final do XIX, testemunharam a passagem do século e registraram essas impressões por meio de sua arte. Afora essa primeira coincidência, as condições que propiciaram o aparecimento desses dois escritores foram bem diferentes. País colonizador, contexto histórico e estético, trajetória de vida, esses fatores podem ter sido decisivos para os distintos olhares lançados para os subúrbios de duas grandes cidades: Buenos Aires e Rio de Janeiro.

É possível obter pequena amostra das feições do subúrbio carioca a partir das crônicas publicadas por Lima Barreto em jornais do Rio de Janeiro ao final de sua curta vida, embora as impressões do autor sobre esse espaço estejam espalhadas ao longo dos seus sete romances, mais de 150 contos e quase 400 crônicas. O material, portanto, é farto, mas as dificuldades maiores de quem se debruça sobre esse campo de estudo começam pela delimitação do território de peculiaridades que é o subúrbio ou arrabalde para uns ou bairro para outros. A definição de "ponto médio entre o campo e a cidade" mostra-se por demais superficial para necessidades de caráter científico. As investigações sobre tal conceito identificam, a certa altura do século XX, uma virada na interpretação do vocábulo, o que Fernandes (2011) nomeou de "rapto ideológico da categoria subúrbio". Segundo esse estudioso, até o final do século XIX a palavra não possuía qualquer sentido depreciativo, designando, à semelhança do vocábulo "arrabalde", as periferias urbanas com grande número de residências de camadas superiores. Assim, a conclusão do autor aponta para um "conceito carioca" de subúrbio, gerado por uma estratégia de desmoralização da classe trabalhadora na cidade do Rio de Janeiro, já que os bairros populares, servidos por linhas ferroviárias, desprestigiados 
tanto do ponto de vista social quanto do poder público, permaneceram com a denominação de subúrbio. E essa virada conceitual dá-se, coincidentemente, com a reforma urbana empreendida por Pereira Passos no início do século XX.

Estabelecido o conceito, Fernandes (2011) lembra que a posição periférica e extramuros é a característica menos variante, na história do vocábulo, mas que se altera quando se trata do subúrbio carioca, de aspecto urbano similar ao da cidade, do centro. Este seria um primeiro aspecto da conformação do subúrbio carioca. O segundo aspecto seria sua referência quase exclusiva e obrigatória para os bairros ferroviários e populares no Rio de Janeiro, associação já prevista, na década de 60, pelo historiador Lewis Mumford (1982), que investigou o fenômeno do subúrbio nos Estados Unidos. Sem dúvida é preciso guardar as devidas proporções entre os subúrbios em cidades americanas como Cleveland e Chicago e os do Rio de Janeiro, mas Fernandes (2011) reafirma esse traço distintivo no caso brasileiro: "[a] identidade entre subúrbio e transporte ferroviário é tão forte que Soares (1960, p.197) verificou que não se denomina subúrbio onde não há trem, mesmo que sejam áreas periféricas, com baixa densidade populacional e outras características próprias aos subúrbios em geral” (p. 35). O percurso que Fernandes traça leva-o ainda a concluir que "[é] a classe social que determina o que é subúrbio [no Rio de Janeiro], a geografia não importa” (2011, p. 38).

Alguns pontos de aproximação com as formulações teóricas de Fernandes (2011), no que se refere à presença do trem, são muito evidentes nas crônicas escritas no final da vida do autor carioca. "O trem dos subúrbios", texto publicado no jornal Gazeta de Notícias em 21 de dezembro de 1921, tem o mérito de utilizar o meio de transporte para realizar um legítimo estudo dos tipos urbanos daquela região da cidade. Partindo da observação de um desenho do artista francês Honoré Daumier, intitulado "Un Wagon de 3ième Classe", o cronista compara a situação-título retratada com a segunda classe do trem que sulca os subúrbios cariocas, meio de transporte utilizado diariamente pelo autor. A intensidade do impacto do desenho sobre a percepção do cronista traz à tona a força de uma imagem na construção de todo um imaginário já bastante alimentado pelas narrativas de viagem (na maioria das vezes orais, feitas pelos integrantes da elite carioca, que viajavam à França), pela própria iconografia, pela literatura e pelos jornais que circulavam ou que eram enviados de Paris por amigos que lá estavam. A atenção do cronista carioca, até mesmo devido à sua origem humilde, volta-se para essa pequena janela parisiense que se abre através do desenho de Daumier. E essa abertura revela personagens e uma realidade muito familiar, embora exale uma atmosfera diversa daquela que o cronista presenciava todos os dias ao deslocar-se para o centro da cidade, 
em que pese o fato de utilizar, como revela mais adiante, os vagões de primeira classe: "[h]abitualmente não viajo em segunda classe; mas tenho viajado, não só, às vezes, por necessidade, como também, em certas outras por puro prazer. Viajo quase sempre de primeira classe e isso, desde muito tempo" (LIMA BARRETO, 2004, p. 468).

E, logo, a comparação entre os dois ambientes, o de lá e o de cá, torna-se inevitável. Segundo a percepção do autor, no Brasil as pessoas não se sentem diminuídas por andarem num vagão que não o de primeira classe. A pequena classe média da época - soldados de polícia, guardas civis, serventes de secretarias do governo - embora humilde, não se julga infeliz ou sofredora, como se pode atestar na ilustração de Daumier.

A heterogeneidade dos tipos e a multiplicidade étnica também são assinaladas pelo cronista como característica do vagão carioca:

Só alguns e, em geral, os operários é que esmaltam no rosto angústia e desânimo. Porém, a indumentária variada merecia que um lápis hábil a registrasse. Aquelas crioulas e mulatas inteiramente de branco, branco vestido, meias, sapatos, ao lado de portugueses ainda com restos de vestuários da terra natal; os uniformes de cáqui das corporações; os em mangas de camisa e algum exótico jaquetão de inverno europeu, acompanhado do indefectível cachimbo. (LIMA BARRETO, p. 467)

Essa radiografia sociológica empreendida pelo autor tem raízes profundas, de cerca de vinte anos, quando, recém-chegado ao subúrbio, depois de atestada a incapacidade mental do pai e, consequentemente, a necessidade de o filho mais velho assumir a chefia da família, Lima Barreto sentia-se diminuído diante do olhar escrutinador dos demais passageiros do vagão de primeira classe. Mas o constrangimento aí não era o do homem calejado pelas dificuldades e pelo preconceito, do crítico mordaz às aparências e do observador experiente que escreve naquele final de 1921. Aquele rapaz que sofria com o olhar de reprovação alheio tinha 22 anos e até então caminhava para uma posição de igualdade ou até superior aos companheiros de vagão, pois era, até pouco tempo, estudante da Escola Politécnica:

Quando, há quase vinte anos, fui morar nos subúrbios, o trem me irritava. A presunção, o pedantismo, a arrogância e o desdém com que olhavam as minhas roupas desfiadas e verdoengas, sacudiam-me os nervos e davam-me ânimos de revolta. Hoje, porém, não me causa senão riso a importância dos magnatas suburbanos. Esses burocratas faustosos, esses escrivães, esses doutores de secretaria, sei bem como são títeres de politicões e politiquinhos. (LIMA BARRETO, p. 468) 
No entanto, o cronista nota que estes tipos se evidenciam no trem, a sua atmosfera própria que os realça desmedidamente. $\mathrm{Na}$ rua do Ouvidor, ao desembarcarem, desaparecem na multidão. O vagão do subúrbio, assim, é o lugar por excelência desses personagens, os "cupins de secretaria e escritórios", e o trem se torna o meio de passagem do notável para o anônimo.

O que se depreende desse pequeno recorte, tanto do subúrbio carioca quanto da obra do autor recolhida nos jornais, é uma representação focada no componente humano daquele espaço, embora a questão da territorialidade não esteja ausente porque o testemunho se dá a partir do trem, espaço de transição entre os dois mundos: o particular e o público, o informal e o formal, o essencial e o das aparências. Sem dúvida trata-se de uma visão em trânsito, focada nas pessoas que saem do subúrbio diariamente e confrontam-se com costumes e práticas do centro do Rio. Mas há outros textos do mesmo autor retratando personagens que raramente ultrapassam os limites do trem, aqueles que fazem exclusivamente do bairro o seu mundo.

Já o subúrbio argentino ganha outra configuração nas elaborações teóricas em língua espanhola. O bairro abrangeria uma ou mais quadras na vizinhança, sem modelo fixo. "Constitui claramente uma subdivisão do subúrbio, ainda que escritores e políticos, muitas vezes, utilizem bairro como sinônimo de subúrbio.” (SABUGO, 2004, p. 46 - tradução nossa).

O status que o bairro goza no imaginário portenho, pode-se constatar desde já, é muito diferente do caso brasileiro. Aqui a "cidade maravilhosa" povoa os sonhos dos brasileiros de norte a sul do país como locus amoenus nacional, lugar onde morro e "asfalto" conviveriam em plena harmonia e onde o morro não goza da "felicidade de arranha-céu/ Pois quem mora lá no morro/ Já vive pertinho do céu”, no dizer de Herivelto Martins numa canção de 1942, Ave Maria no morro. No caso de nossos vizinhos, "nas dezenas de milhares de tangos de Buenos Aires quase sempre se menciona o bairro, mas poucas vezes a cidade" (BARELA; SABUGO, 2004, p. 8). A cultura do bairro é, pois, muito peculiar aos argentinos, sobretudo no que se refere aos portenhos. Na bibliografia sobre o tema emprega-se, inclusive, o termo "geração" para diferentes épocas na evolução do bairro. A primeira geração abrangeria os anos de 1729 até o final do século XIX, quando as grandes levas de imigrantes, a construção do porto, os sistemas mecânicos de transporte, o ingresso da cidade no sistema capitalista bem como a expansão territorial de Buenos Aires modificaram profundamente a configuração urbana da capital. É dessa transição da primeira para a segunda geração 
que se apresenta como testemunha, por meio de sua poesia, Evaristo Carriego, que publica, em 1908, Misas herejes.

Prignano (2008, p. 71), do ponto de vista histórico, aponta os estudos do bairro como trincheira de resistência, por parte dos países em desenvolvimento - como é o caso da maioria das nações latino-americanas — frente à força intimidadora da globalização. Diz o autor:

Um instrumento válido, entre outros, é a bairrologia, que, estendida a qualquer parte do mundo, apresenta-se como uma construção possível para descobrir e entender a história emotiva e pessoal dos povos, seu habitat primário e seu modo de ser. Dito de outro modo, a partir da bairrologia é possível afirmar a diversidade cultural em qualquer espaço urbano básico que se manifeste, estimulando a bairralidade própria e inseparável de cada vizinho, condição talvez omitida por outras histórias. (Tradução nossa.)

Quando o autor cita, acima, “outras histórias” está se referindo ao estágio dos estudos historiográficos anterior ao aparecimento da "Nova História", fenômeno científico que também data de meados do século $\mathrm{XX}$, e que se contrapõe à existência de uma única história, focada nos heróis que "fizeram a História". Essa história fragmentada, do cotidiano, da criança, das mulheres, do amor, de muitos outros assuntos, privilegia setores da população até então totalmente esquecidos, como é o caso dos habitantes dos bairros, ou subúrbios. Podemos ver que essa explicação vem de alguma forma complementar o que preconizou Fernandes (2011) anteriormente, pois procura olhar o bairro a partir de um prisma interno, mas que, sem dúvida, carece de uma delimitação geográfica, espacial. Davero (apud Vega e Alarcón, 2008, p. 37) ensaia essa aproximação entre o espacial e o social quando diz que o bairro é um espaço

onde se produz o primeiro contato extra-familiar do indivíduo, sendo o âmbito da convivência solidária. É a parte da cidade, localidade ou povoado, compreendida entre determinados limites (ruas, avenidas, acidentes geográficos) que constitui uma unidade administrativa ou de fato, depende do governo do município e apresenta, habitualmente, características de edificações e de seus moradores muito particulares. (Tradução nossa.)

É justamente esse o bairro que Lima Barreto e Carriego nos apresentam por meio da representação literária do espaço e das pessoas que nele habitam e circulam, e pelo qual eles mesmos circularam quase concomitantemente, embora cada um estivesse no seu respectivo território. Carriego nasceu na província de Entre Rios, no norte 
argentino, e antes de se estabelecer no bairro portenho de Palermo, com seis anos, viveu dois anos na cidade de La Plata, então recentemente fundada. O bairro que a família escolheu para instalar-se era, então, um bairro de fronteira, um subúrbio, quase fora dos limites da cidade, que eram demarcados pelo Arroyo Maldonado, hoje totalmente canalizado desde a sua origem. Ali cresceu aquele que seria chamado pelo mundialmente conhecido Jorge Luis Borges, mais tarde, de "o primeiro espectador de nossos bairros pobres" (BORGES, 1998, p. 149).

Mas há algo que diferencia a condição de ambos os descobridores dos subúrbios literários em Buenos Aires e no Rio de Janeiro: enquanto Lima foi “empurrado" para a periferia da cidade, por contingências familiares, depois de a família morar durante anos na Ilha do Governador, Carriego escolheu o arrabalde espontaneamente e, conforme a família ia melhorando de vida, foi modificando o endereço, mas sempre na periferia. Apesar dessa sua posição geográfica situada à margem, o poeta nunca deixou de relacionar-se com a intelectualidade que frequentava os cafés do centro. E a escolha estética de Carriego por representar a sua patria chica (expressão usada várias vezes por Borges para designar o bairro portenho) não provocou nenhuma resistência por parte dos meios intelectuais. Ao contrário. Sua primeira obra, Misas herejes, foi generosamente recebida pelos amigos e pela crítica local. O caso de Lima Barreto foi completamente antagônico. Recordações do escrivão Isaías Caminha, publicado em 1909, só encontrou editor em Portugal pela intervenção do amigo Antonio Noronha dos Santos. E a obra foi recebida no Brasil, pela crítica, com a mais absoluta indiferença.

Em seu Evaristo Carriego (1930), Jorge Luis Borges não se exime das críticas quando afirma que Carriego, na maioria dos poemas da segunda obra, La canción del barrio, apela somente para a piedade do leitor, à medida que retrata insistentemente a "mera mortalidade ou infortúnio" (aqui recuperando a expressão de Bernard Shaw). Mas nem tudo está perdido na visão do célebre autor. Há trechos capazes de exemplificar "refinamentos de ternura, invenções e intuições da ternura", como se verifica no poema que abre o volume. Em "El camino de nuestra casa", Evaristo Carriego personifica as ruas que o levam todos os dias ao encontro da família. No entanto, aqui, a linguagem poética e o tom melancólico conferem outro aspecto ao bairro portenho. Aqui não há trens, mas o realejo, elemento recorrente na poesia carreguiana, leva consigo "El alma del subúrbio": "nos eres familiar como una cosa que fuese nuestra, familiar [...] en la monotonía dolorida del quejoso organillo que tanto gusta oir nuestra vecina, la de los ojos tristes...”(CIRUZZI, 1999, p. 123). 
No decorrer das quatro partes do poema, Carriego compõe essa atmosfera familiar com elementos como as ruas, as árvores, a alegria dos rapazes, os rostos dos velhos amigos ou com as histórias íntimas que circulam no bairro. A personificação completa-se com a voz poética dirigindo-se ao "camino" como num diálogo no qual menciona os elementos do passado que retornam à sua memória durante o trajeto: "tus piedras parece que guardasen en secreto el rumor de los pasos familiares que se apagaron hace tiempo.[...] eres como un rostro querido que hubiéramos besado muchas veces: i tanto te conocemos!” (CIRUZZI, p. 123).

Na terceira parte do poema a direção da voz muda e passa não mais a dirigir-se ao "camino" mas, em terceira pessoa, lembra "de la muchacha modesta y pensativa que hemos visto envejecer sin novio... resignada!” E se pensávamos que a nostalgia e a melancolia tinham atingido grau máximo, o poeta conclui sua reflexão lembrando as pessoas que vem e vão da vizinhança, ou da vida, sem que, às vezes, tenham oportunidade de despedir-se. E dos moradores do bairro, passando pelos vizinhos, a memória vai se aproximando do próprio poeta, que prevê, assim, o seu desaparecimento silencioso: “¡Oh, los vecinos que no nos darán más los buenos días! Pensar que alguna vez nosotros también por nuestro lado nos iremos, quién sabe dónde, silenciosamente como se fueron ellos..."

De alto poder simbólico, esse texto de Carriego, que abre o volume de poesias La canción del barrio, publicado postumamente pelo irmão e pelos amigos do poeta, já traz o germe da perda em seu bojo. Em 1909, um ano depois de publicar seu primeiro livro, Carriego perde o pai, Evaristo Nicanor. Três anos depois, a tuberculose vitima o próprio escritor que, segundo sua biógrafa, tinha na sua rua de moradia - a Calle Honduras, no bairro de Palermo - a inspiração para seus versos. Cada uma das partes do poema parece constituir um passo ao longo do "camino" da rua para a casa, mas também dos elementos externos (árvores, ruas, vizinhos,...) em direção ao próprio sujeito poético. O olhar do poeta percorre um trajeto de fora para dentro, prevendo as consequências da passagem do tempo e a chegada da própria morte, em incerta hora, como comprovam o final em reticências e o tamanho menor da estrofe, interrompida no sexto verso.

Em que pese, desse modo, a diferença de tom entre as duas representações literárias dos subúrbios de Buenos Aires e do Rio de Janeiro, ambos os autores voltam seus olhares para o que Prignano (2008) chamou de "outras histórias", isto é, ambos empreendem "narrativas" possíveis de personagens até aí totalmente anônimos dada a sua condição espacial periférica. Os soldados de polícia, os rapazes casadoiros, os 
imitadores da moda; os "muchachos", os moradores de um arrabalde portenho, uma moça que ficou sem casar, todos personagens subalternos de histórias jamais contadas até então. Se o trem executa uma função primordial num caso, a própria rua, personificada no ente mais querido do poeta, é que une os elementos da memória do morador do subúrbio. E se a comparação se estende para os respectivos contextos, a pergunta que fica é: Lima Barreto não teria mais razões do que Carriego para pintar seu subúrbio com as tintas da melancolia?

Daumiers do seu tempo e dos seus espaços, ambos esboçaram, cada um com suas tintas, fotografias verbais de um passado que, muitas vezes, nem encontra correspondência na iconografia da época. Mas esses registros, sem dúvida, mostram mais do que simples rostos, feições de casas e de ruas. Revelam a alma de subúrbios que desaparecem no tempo.

\section{REFERÊNCIAS BIBLIOGRÁFICAS}

BARELA, Liliana; SABUGO, Mario. Prólogo: venimos de los Barrios. In:

Buenos Aires: el libro del barrio: teorias y definiciones. Buenos Aires: Instituto Histórico de la Ciudad de Buenos Aires, 2004.

BORGES, Jorge Luis. Evaristo Carriego. In: Obras completas. (1923 1949). v.1. São Paulo: Globo, 1998.

CIRUZZI, Marcela. (org.) Obra completa de Evaristo Carriego. Buenos Aires:

Corregidor, 1999.

RIVAS, Pierre. Paris como a Capital Literária da América Latina. In. CHIAPPINI, Ligia; AGUIAR, Flavio Wolf de. (orgs.) Literatura e história na América Latina. São Paulo: EDUSP, 2001, p. 99 - 114.

FERNANDES, Nelson da Nóbrega. O rapto ideológico da categoria subúrbio: Rio de Janeiro 1858/1945. Rio de Janeiro: Apicuri, 2011.

LIMA BARRETO, Afonso Henriques de. O trem dos subúrbios. In. . Toda crônica. Apresentação e notas Beatriz Resende; organização Raquel Valença. v.2. Rio de Janeiro: Agir, 2004.

MUMFORD, Lewis. A Cidade na história. São Paulo (SP): M. Fontes, 1982. 
PRIGNANO, Angel. Barriologia e globalización. In. Barriologia e diversidad cultural. Buenos Aires: Ciccus, 2008.

SABUGO, Mario. El barrio, al fin de cuentas. In: BARELA, Liliana; SABUGO, Mario. Buenos Aires: el libro del barrio: teorias y definiciones. Buenos Aires: Instituto Histórico de la Ciudad de Buenos Aires, 2004.

SCHWARTZ, Jorge. Vanguarda e cosmopolitismo na década de 20. São Paulo : Perspectiva, 1983.

VEGA, Joaquim; ALARCÓN, Juan. El barrio como unidad operativa para el desarollo local. Buenos Aires: Lúmen, 2008. 